Thorax (1954), 9, 304.

\title{
PULMONARY INFARCTS ASSOCIATED WITH BRONCHOGENIC CARCINOMA
}

\author{
BY \\ W. J. HANBURY, R. J. R. CURETON, AND G. SIMON \\ From St. Bartholomew's Hospital, London
}

(RECEIVED FOR PUBLICATION JUNE 27, 1954)

Clinically silent pulmonary infarcts may be large enough to cast a shadow on a chest radiograph, and, unless the possibility of this type of lesion is borne in mind, serious errors in treatment may occasionally arise. We therefore present an account of 10 such cases, all associated with bronchogenic carcinoma. Although pulmonary infarcts due to thrombo-embolism are fairly common, there is no reference in many of the standard textbooks to their occurrence in cases of bronchial carcinoma, and the literature contains few examples.

Pallasse and Damez (1933) reported a case of pulmonary cancer with haemorrhagic pleurisy, pulmonary infarction, and acute pericarditis, and Monges, Poinso, and Lumbroso (1936) described the diagnostic difficulties of a case of primary cancer of the lung with an oval radiographic image corresponding to coexisting infarction. Another case of adenocarcinoma of the lung with pulmonary infarcts was reported from Massachusetts General Hospital (1946), when Mallory commented on the rarity of the association and on the fact that infarcts could result from constriction of the major blood vessels by tumour, apparently without recognizable arterial thrombosis. Apart from these reported cases, no other references to the subject were found in the recent literature.

The 10 cases described in this paper were co!lected from a series of 100 cases of pneumonectomy performed for bronchogenic carcinoma, making an incidence of $10 \%$.

\section{Clinical, Radiological, and Pathological FindINGS}

Although no unusual pathological features have been observed in this study, the lesions have in some instances been the object of much speculation during the radiological investigation, and co-operation between radiologist and pathologist has yielded some interesting information, showing that a fairly close correlation of findings can be made. From the radiological point of view the cases may be grouped conveniently under three headings, and for the sake of clarity and cohesion the pathological features will be described in the same order concurrently with the clinical and radiological findings. The three groups comprise :

(1) Well-defined peripheral infarcts completely separate from the main tumour mass ; (2) less welldefined infarcts in an axillary position; (3) infarcts completely obscured by surrounding inflammatory changes, airless lung tissue, or other causes.

Pre-operatively, the patients were active and had no signs of peripheral venous thrombosis, and no emboli were subsequently found in the lungs The post-operative course of all 10 cases was satisfactory.

\section{Group 1: Peripheral Infarcts Separate from THE Tumour MASS}

CASE 1.-A man aged 55 had had haemoptyses three months and one week before. The radiograph (Fig. 1) showed an opacity in the region of the lingula (in the lateral view, the lingula was seen to be rather shrunken). In addition there was an ill-defined $2 \mathrm{~cm}$. area of clouding just below the clavicle. This was mistakenly considered to be an ipsilateral secondary deposit.

Pathology.-The specimen, a left lung, contained a carcinoma, $5 \times 3 \times 2.5 \mathrm{~cm}$., arising from the lingular bronchus. A $5 \times 3 \times 4 \mathrm{~cm}$. wedge-shaped infarct was present in the periphery of the apicoposterior segment of the upper lobe (Figs. 2 and 3). A large upper lobe branch of the pulmonary artery was greatly compressed by neoplastic tissue, and a large vein passed through the centre of the tumour mass.

Histology.-The neoplasm is a poorly differentiated squamous cell carcinoma. The infarct appears moderately recent, but shows some evidence of peripheral organization. The artery supplying this region shows neoplastic infiltration of its wall, but, although some proliferative endarteritis is present, no thrombi are seen (Fig. 4).

CASE 2.-A man aged 50 had recently had several small haemoptyses. The radiograph (Fig. 5) showed 


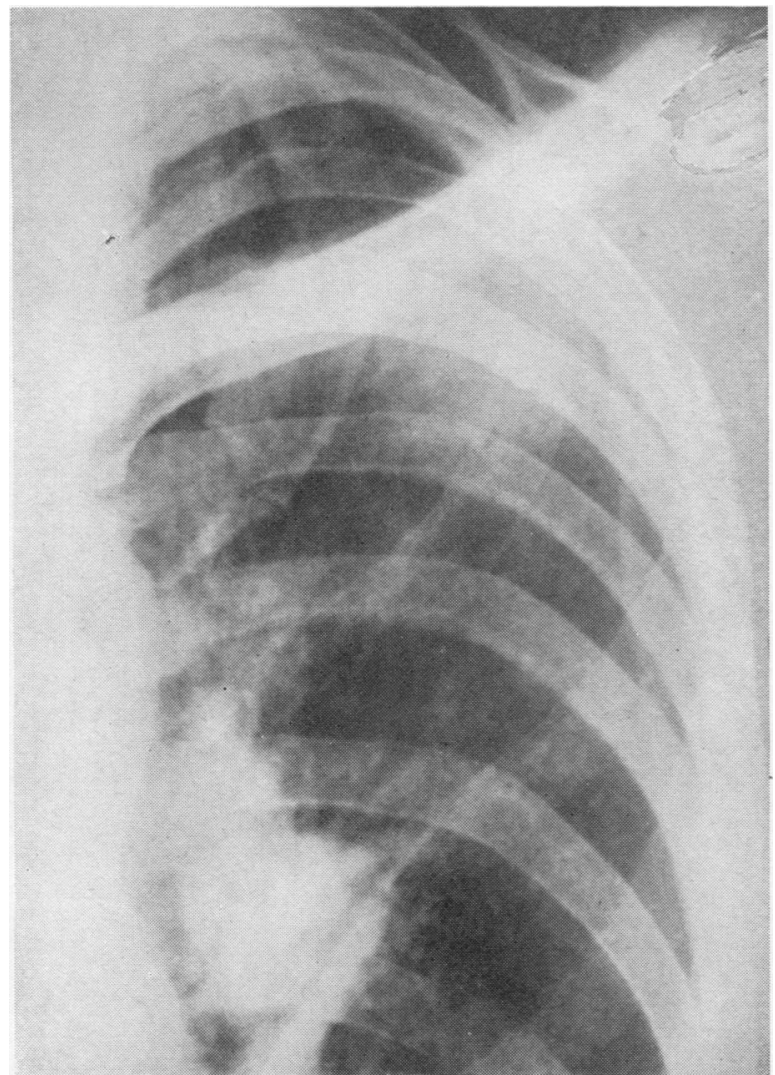

FIG. 1.-Case 1: the poorly defined $2 \mathrm{~cm}$. shadow near the hilum represents the neoplasm, the poorly defined $2 \mathrm{~cm}$. shadow in the axilla just below the clavicle the infarct.
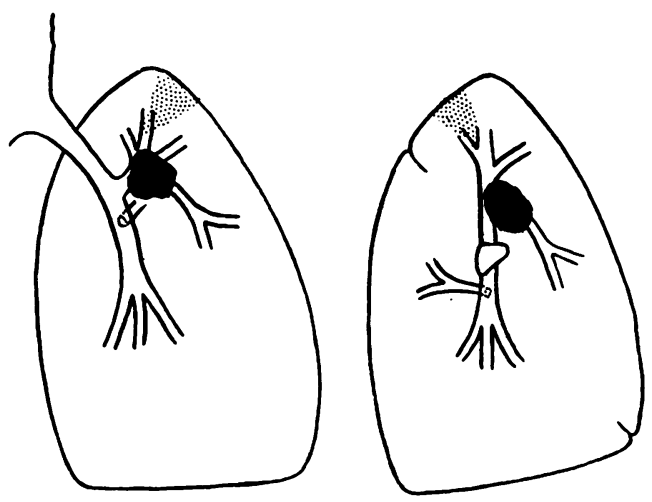

FIG. 3.-Case 1: diagrams showing positions of carcinoma (black) and infarct (dotted).

FiG. 4.-Case 1: photomicrograph of wall of artery supplying infarcted region of lung, showing neoplastic infiltration and proliferative endarteritis. (Haematoxylin and eosin, $\times 90$.)

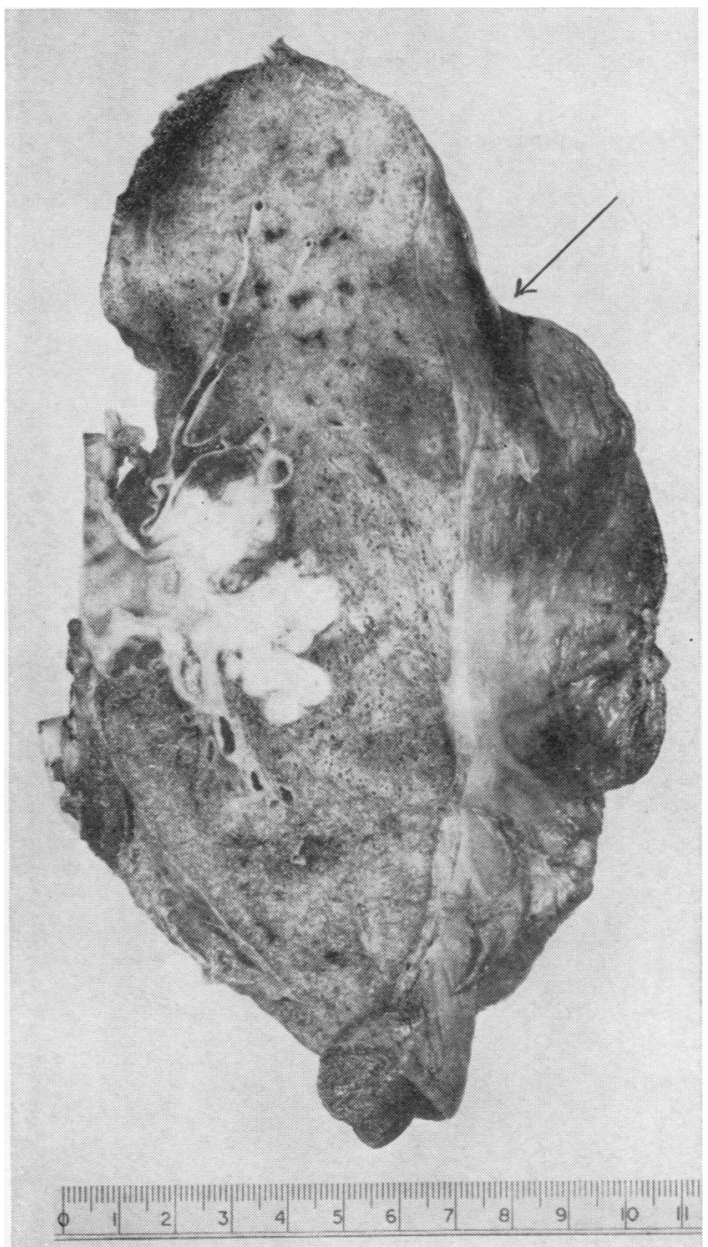

Fig. 2.-Case 1: cut surface of left lung showing carcinoma of lingular bronchus with peripheral infarct (arrowed) in apicoposterior segment of upper lobe. 
Fig. 5.-Case 2: tomogram of the left upper zone. Two well defined circular shadows, $1.5 \mathrm{~cm}$. in diameter, are seen towards the axilla just below the clavicle, lying fairly posteriorly.

FIG. 6.-Case 2: diagrams of leftl ung showing positions of carcinoma (black) and dumbbell-shaped infarct (dotted).

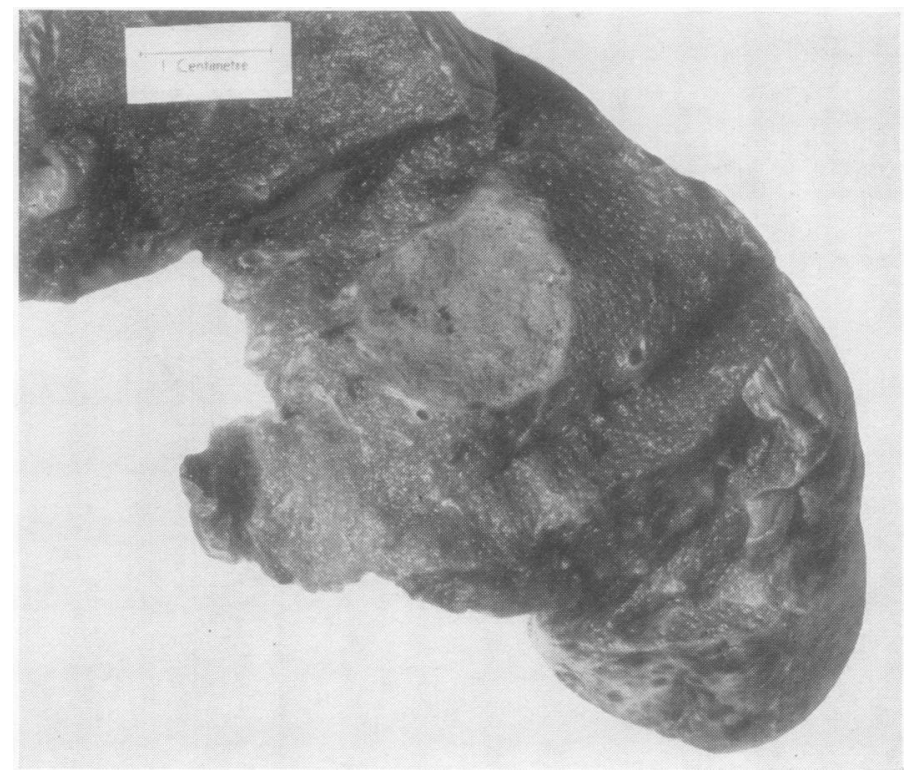

FIG. 5

FIG. 7

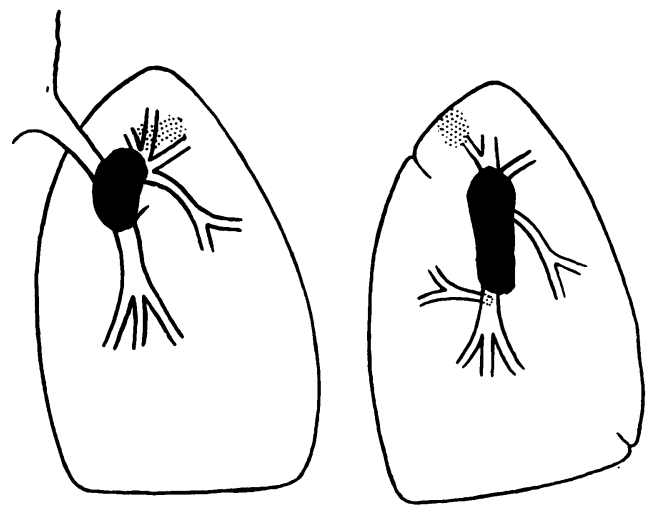

FIG. 6

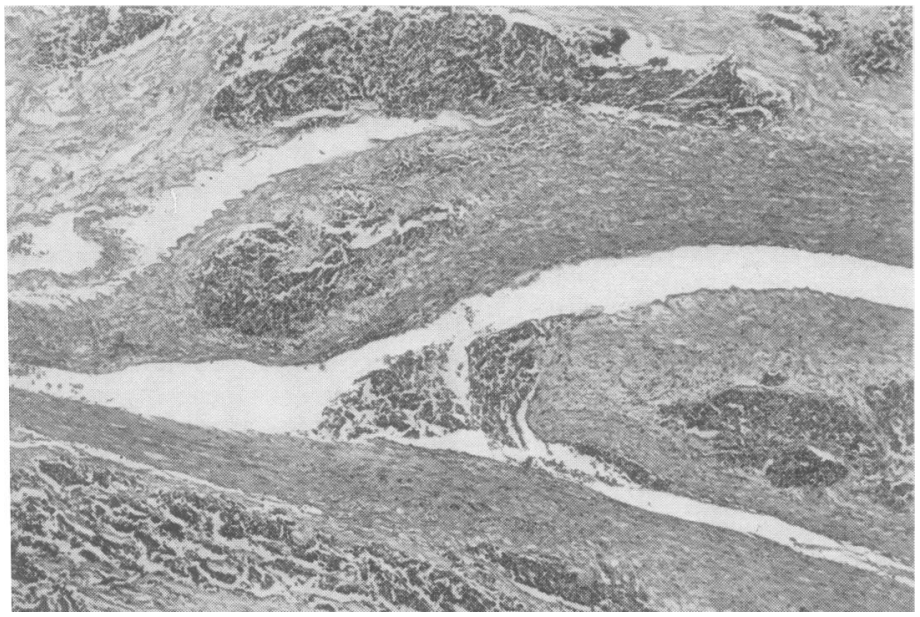

Fig. 7.-Case 2: cut surface of part of apico-posterior segment showing area of infarction.

Fig. 8.-Case 2: photomicrograph of branch of pulmonary artery near hilum, showing neoplastic infiltration and organized thrombus. (Haematoxylin and eosin, $\times 40$.)

FiG. 8 
two $1 \mathrm{~cm}$. circular shadows in the outer third of the left upper zone. Tuberculosis was considered a possibility. No second shadow was seen nearer to the hilum at the site where a neoplasm was subsequently found. Bronchoscopy showed no abnormality, but the development of diminished breath sounds in the left upper zone suggested a bronchostenosis. A thoracotomy was therefore undertaken. The neoplasm was then identified near the main bronchus, and a pneumonectomy was performed.

The specimen, a left lung, contained an $8 \times 4 \times$ $4 \mathrm{~cm}$. neoplasm involving the main bronchus but apparently originating in the branch to the upper lobe. A dumbbell-shaped infarct, maximum diameter $1.5 \mathrm{~cm}$., was situated in the periphery of the apicoposterior segment of the upper lobe (Figs. 6 and 7). The two parts of this infarct corresponded in size to the two shadows seen on the radiograph.

The neoplasm shows the features of a poorly differentiated squamous cell carcinoma. The infarct appears fairly old, with almost complete disappearance of nuclei and with much peripheral organization and fibrosis. Some branches of the pulmonary artery near the hilum are infiltrated by neoplastic tissue, and contain organized thrombi (Fig. 8).

CASE 3.-A man aged 59 had for two years had increasing dyspnoea and some cough. Recently the cough had become worse and the sputum blood-
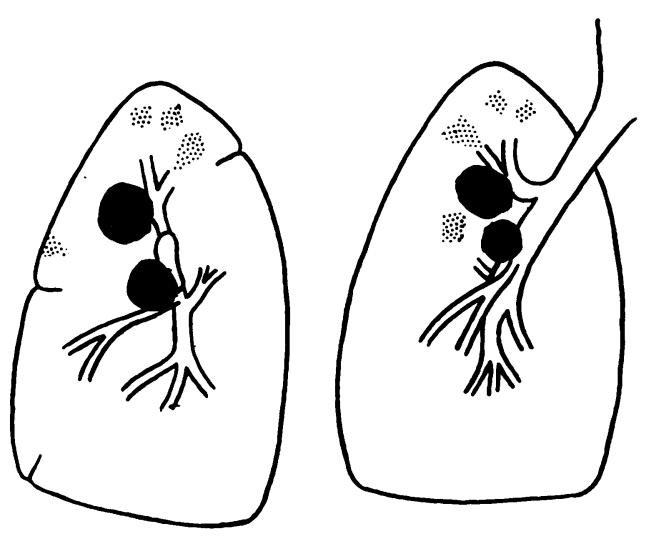

Fig. 9. - Case 3: diagrams of right lung showing positions of two carcinomatous masses (black) and four infarcts (dotted).

stained. Bronchoscopy showed a carcinoma of the anterior bronchus of the right upper lobe. The radiograph showed the shadow of the neoplasm in the anterior segment of the right upper lobe. A $1 \mathrm{~cm}$. ill-defined area of clouding towards the axilla probably represented one of the four infarcts found subsequently. The other three were not seen. No tomogram was taken.

The specimen, a right lung, contained two neoplastic masses. One, $3.5 \mathrm{~cm}$. in diameter, was situated in relation to the anterior segmental bronchus in the upper lobe. A second mass, $3 \mathrm{~cm}$. in diameter and
$1 \mathrm{~cm}$. below the first, was involving the septum between the upper and middle lobes. Four infarcts were found, all in the upper lobe (Fig. 9), varying from 1 to $2 \mathrm{~cm}$. in diameter, and only one of which was subpleural. None of the larger arteries showed evidence of neoplastic infiltration or thrombosis.

The tumour is a poorly differentiated squamous cell carcinoma. All the infarcts appear approximately of the same age, are moderately recent, and show surrounding zones of organizing pneumonic exudate. The small arteries adjacent to the infarcts frequently show organizing, recanalizing thrombi.

\section{Group 2: WEDGE-SHAPED INFARCTS IN AN AXILlary Position}

CASE 4.-A man aged 48 was found to have an abnormality on mass radiography. He had recently developed pain in the right side of the chest. Bronchoscopy showed pressure on the lower part of the right main bronchus. The radiograph (Fig. 10) showed a $2 \mathrm{~cm}$. ill-defined area of clouding near the hilum, and a separate, peripheral $5 \mathrm{~cm}$. area of clouding in the axilla at the same level. There was a $1 \mathrm{~cm}$. circular shadow between the two. In the lateral view the shadows were all superimposed in the middle third of the upper lobe.

The specimen, a right lung, contained several carcinomatous nodules in the anterior segment of the

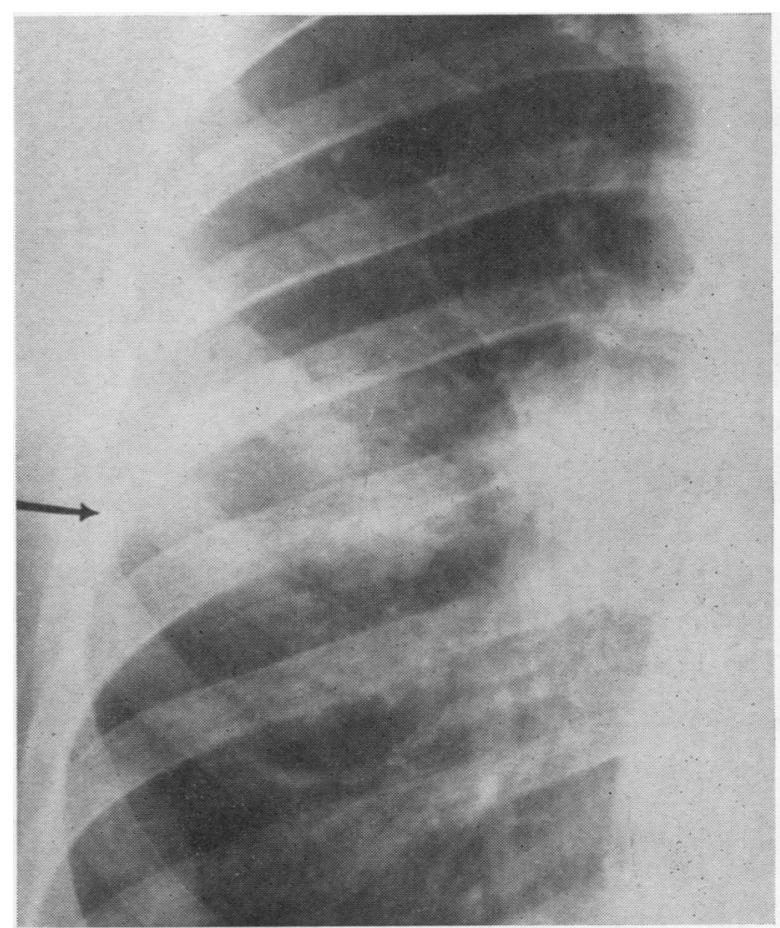

FIG. 10.-Case 4: the 2-cm., ill-defined shadow superimposed on the hilum represents the neoplasm; the larger, wedge-shaped shadow with its base in the axilla (opposite arrow) the infarct. 
upper lobe, and also a tumour mass, $3.5 \times 2.5 \times$ $3 \mathrm{~cm}$., situated in the angle between the upper and descending bronchi. Peripheral to, but lying fairly close to the nodules in the anterior segment, there was an infarct, approximately $5 \times 2 \times 2 \mathrm{~cm}$. (Fig. 11). The anterior segmental branch of the pulmonary artery was considerably compressed by the neoplastic mass at the hilum.

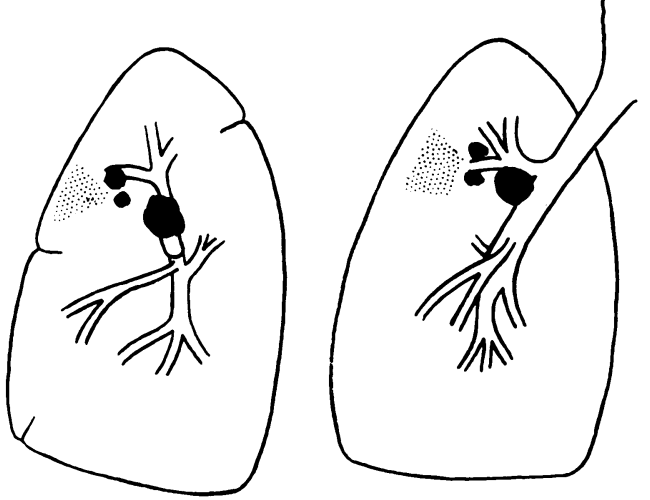

FIG. 11.-Case 4: diagrams of right lung showing positions of carcinomatous masses (black) and infarct (dotted).

The neoplasm is a poorly differentiated adenocarcinoma. Perivascular lymphatic spread of the tumour is very marked, but no thrombosis or neoplastic infiltration of pulmonary arteries is seen outside the infarcted zone. The infarct appears moderately recent, showing only the earliest signs of peripheral organization.

CASE 5.-A man aged 46 had had cough, sputum, fever, and pain in the right chest for eight weeks. This febrile incident persisted and a radiograph was taken. This showed a $5 \mathrm{~cm}$. ill-defined opacity near the hilum, and a separate $5 \mathrm{~cm}$. triangular shadow in the axilla with its apex towards the hilum. The appearances were also very similar to those in Fig. 10. The lateral view showed the shadow near the hilum to extend anteriorly and merge into that of an opaque shrunken lobe, with much elevation of the diaphragm anteriorly. The axillary shadow was in the lower part of the upper lobe. Bronchoscopy revealed a carcinoma occluding the middle lobe bronchus.

The specimen, a right lung, showed a lobulated carcinoma, approximately $4 \mathrm{~cm}$. in diameter, situated in relation to the middle lobe bronchus, and extending also across the interlobar fissure into the base of the upper lobe (Fig. 12). A wedge-shaped peripheral infarct, $5 \times 3 \times 5 \mathrm{~cm}$., was present in the anterior segment of the upper lobe, as shown in the diagram (Fig. 13), and a segmental branch of the pulmonary artery leading to the infarct contained a thrombus. A main branch of the pulmonary artery adjacent to the tumour also contained thrombus.
The tumour is a squamous cell carcinoma. 'The infarct is moderately recent, but shows early organization. The wall of the large pulmonary arterial branch is infiltrated by carcinomatous tissue and filled with thrombus, also showing early organization (Fig. 14).

CASE 6.-A man aged 56 had had six months previously a heavy cold with persistent cough and sputum. He had slowly improved, but recently the sputum was blood-stained. Bronchoscopy showed blood in the right upper lobe orifice, and biopsy revealed an anaplastic carcinoma. The radiograph (Fig. 15) was very similar to that of the previous case ; it showed a $2 \mathrm{~cm}$. hilar opacity and a separate $5 \mathrm{~cm}$. triangular shadow, with its apex towards the hilum, lying in the axillary part of the posterior segment of the upper lobe.

The specimen, a right lung, contained a neoplasm, approximately $4 \mathrm{~cm}$. in diameter, situated near the hilum and apparently arising in the anterior branch of the upper lobe bronchus. The hilar lymph nodes were also extensively infiltrated. In the posterior segment of the upper lobe there was a peripheral infarct $8 \times 7 \times 3 \mathrm{~cm}$. (Figs. 16 and 17). Some main branches of the pulmonary artery were compressed by tumour tissue, but no neoplastic infiltration or thrombosis of any vessel could be seen.

The neoplasm is an oat-cell carcinoma. The infarct appears moderately old, showing considerable peripheral organization. The arteries show no histological evidence of permeation by tumour or of thrombosis.

\section{Group 3: Infarcts Obscured by Changes IN THE SURROUNDING LUNG}

CASE 7.-A man aged 41 was found to have a lung shadow on mass radiography examination. He had no symptoms. Bronchoscopy showed a neoplasm of the left lower lobe bronchus. Radiographs showed a $2 \mathrm{~cm}$. circular shadow in the base of the left lower

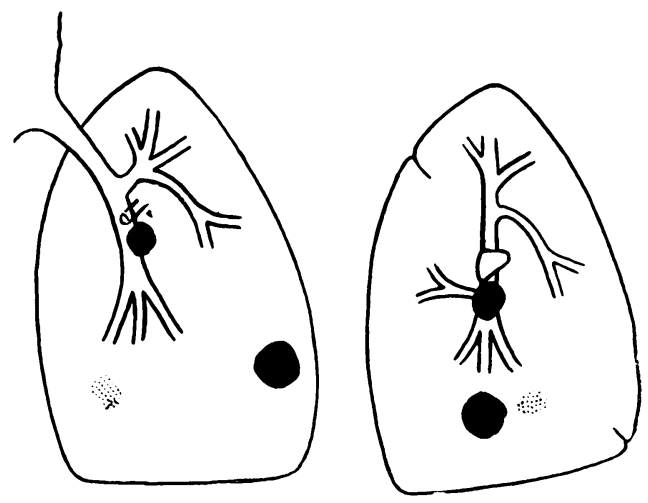

FIG. 18.-Case 7: diagrams of left lung showing positions of carcinomatous masses (black) and infarct (dotted). 
FIG. 12.-Case 5: cut surface of right lung showing carcinoma of middle lobe bronchus and peripheral infarct (arrowed) in anterior segment of upper lobe. A thrombus is present in a main pulmonary arterial branch adjacent to the tumour.

Fig. 13.-Case 5: diagrams showing positions of carcinoma (black) and infarct (dotted).

FIG. 14. - Case 5: photomicrograph of large pulmonary arterial branch infiltrated by carcinoma and filled with thrombus. (Haematoxylin and, eosin, $\times 3$.)
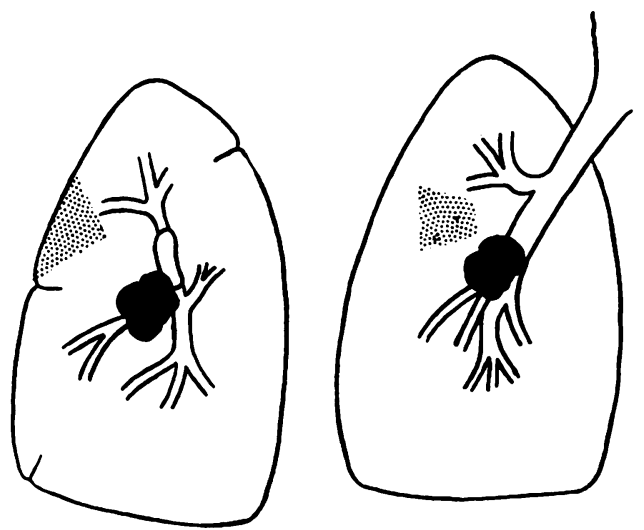

FIG. 13

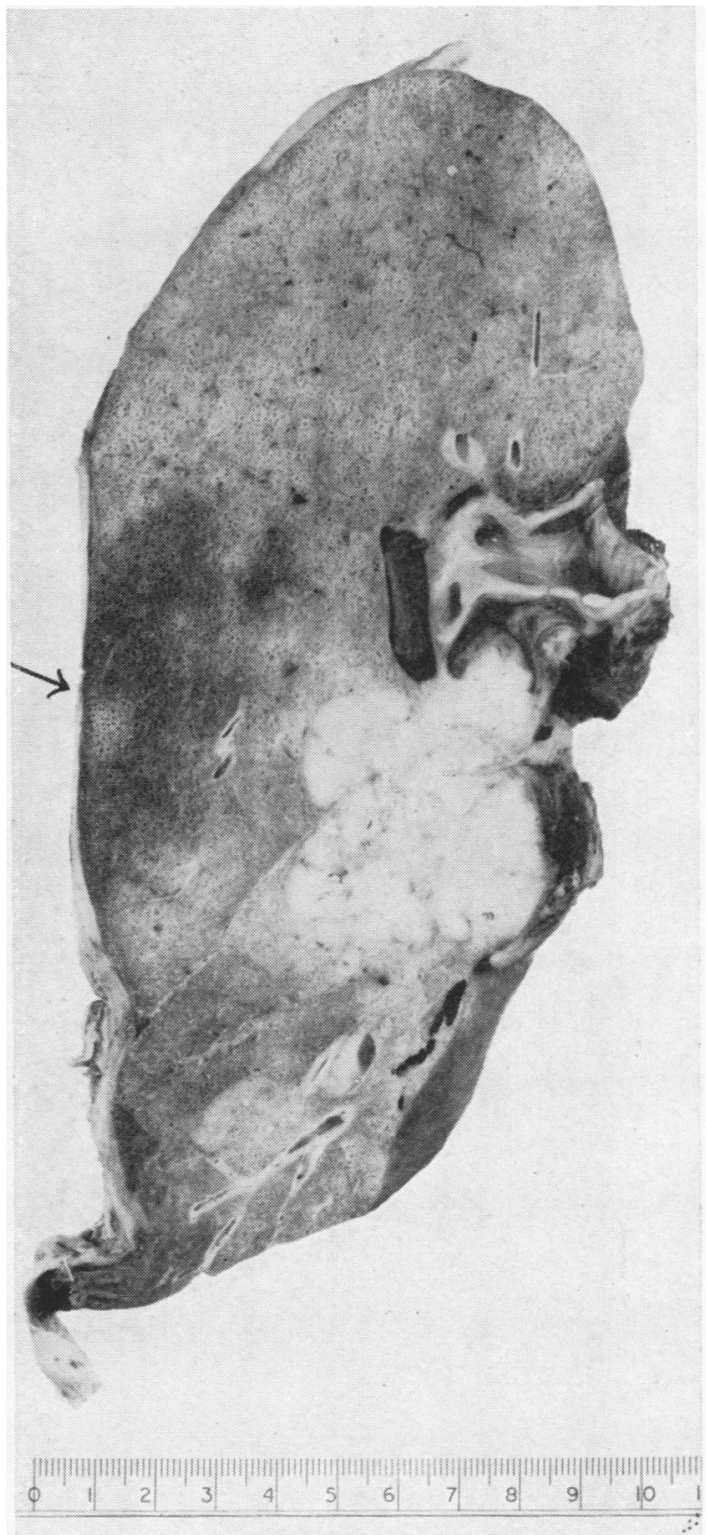

FIG. 12

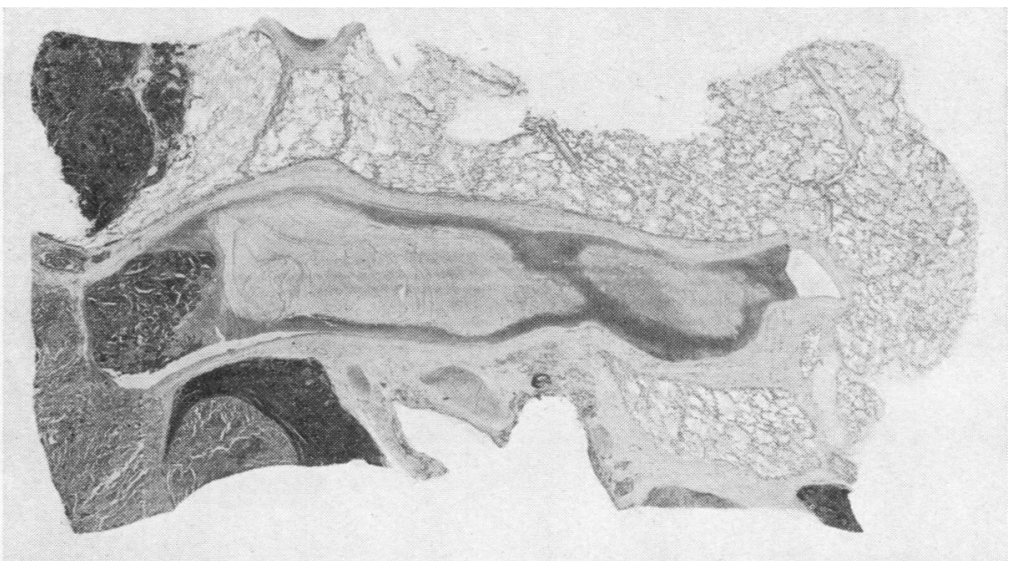




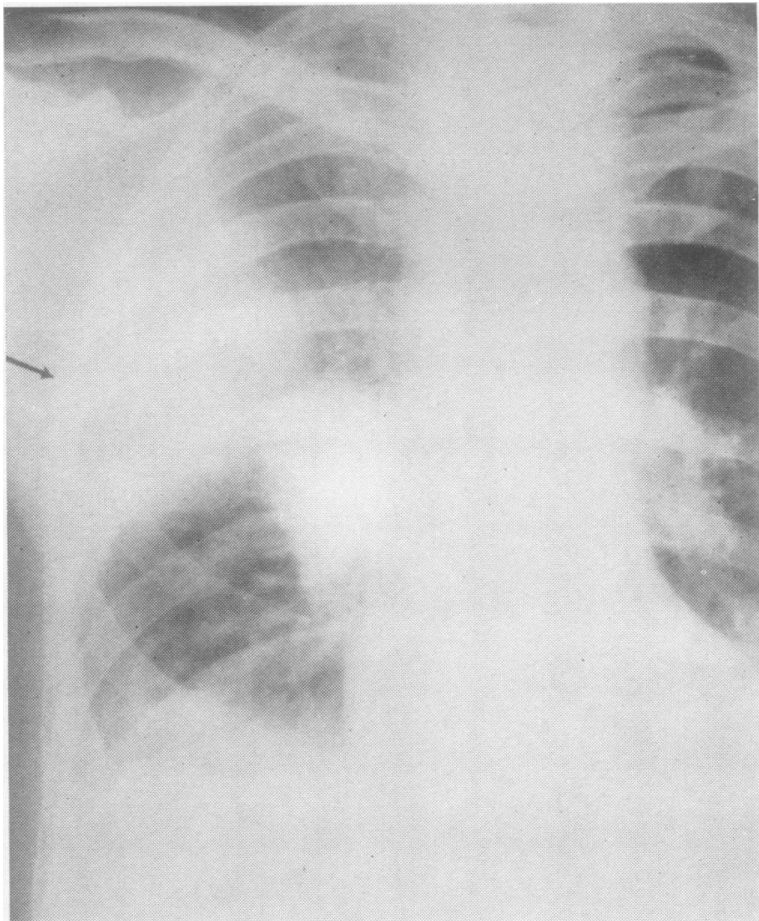

FIG. 15.-Case 6: $2 \mathrm{~cm}$. circular shadow superimposed on the right hilum represents the neoplasm; the wedge-shaped shadow with its base in the axilla (opposite arrow) the infarct.
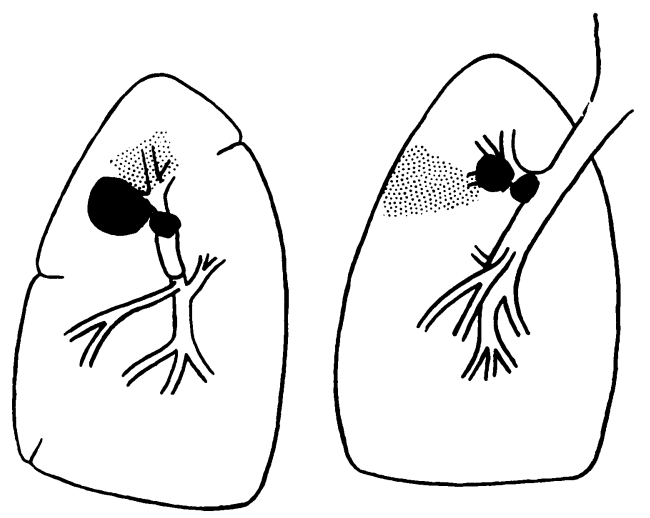

FIG. 17.-Case 6: diagrams showing positions of carcinomatous masses (black) and infarct (dotted). 
lobe, and another shadow near the hilum; the whole lower lobe was shrunken and slightly opaque. The infarct was not identified in the general clouding. No tomograms were taken.

The specimen, a left lung, contained a carcinoma, $2.5 \times 2 \times 2 \mathrm{~cm}$., in relation to the main lower lobe bronchus and another tumour mass, $4 \mathrm{~cm}$. in diameter, situated in the anterior and lateral basal segments. A peripheral infarct, approximately $1 \mathrm{~cm}$. in diameter, was found anterior to the second tumour mass, as shown in the diagram (Fig. 18). No thrombosed vessels were seen.

The tumour is a mucus-secreting adenocarcinoma. There is much perivascular and peribronchial lymphatic permeation by neoplastic tissue, but no vessel walls are seen to be infiltrated by tumour and no thrombi are found. The infarct is fairly recent, with much surrounding inflammatory reaction but no organization.

CASE 8.-A man aged 43 had had, 10 weeks previously, cough and sputum, then two small haemoptyses and fever. Bronchoscopy showed a neoplasm in the left lower lobe. Radiographs showed a single homogeneous opacity representing the neoplasm, a shrumken left lower lobe with its inflammatory changes, and the infarct.

The specimen, a left lung, contained a carcinoma, $5 \times 4 \times 3 \mathrm{~cm}$., situated in relation to the main

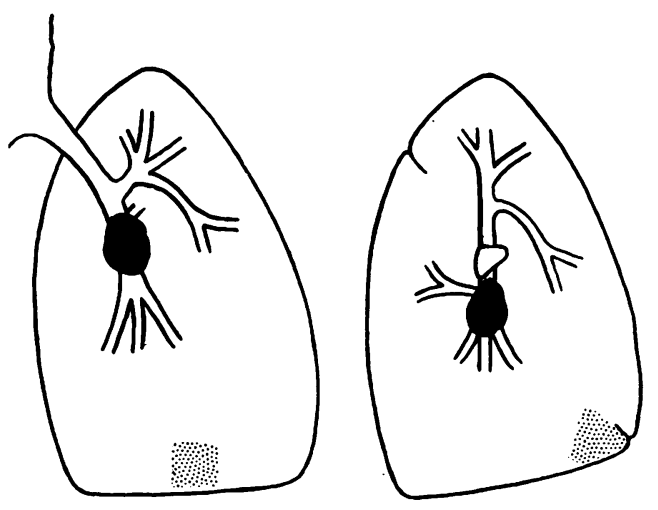

FIG. 19.-Case 8: diagrams of left lung showing positions of carcinoma (black) and infarct (dotted).

lower lobe bronchus. Distal to the growth the lower lobe showed bronchiectasis and much chronic pneumonia. There was also an ill-defined, peripheral, basal infarct, $5 \mathrm{~cm}$. in diameter, as shown in the diagram (Fig. 19), but no thrombosed vessels were found.

The tumour is a poorly differentiated squamous cell carcinoma. The infarct is fairly recent and surrounded by tuberculous bronchopneumonia. The majority of the small arteries show a proliferative endarteritis, but no evidence of neoplastic infiltration or thrombosis.
CASE 9.-A man aged 49 had developed, one month previously, right chest pain, worse on breathing, and two weeks previously had had a small haemoptysis. Bronchoscopy showed a neoplasm of the basal bronchi. Radiographs showed a depressed horizontal fissure, and a homogeneous opacity below, caused partly by a pleural effusion and partly by the airless lower lobe and the neoplasm.

The specimen, a right lung, showed a tumour, $7 \times 4.5 \times 4 \mathrm{~cm}$., in relation to the basal branches of the lower lobe bronchus. In the region of the costo-phrenic angle there was an infarct, approximately $2 \mathrm{~cm}$. in diameter (Fig. 20), adjacent to a chronic empyema cavity. No thrombosed vessels were found.

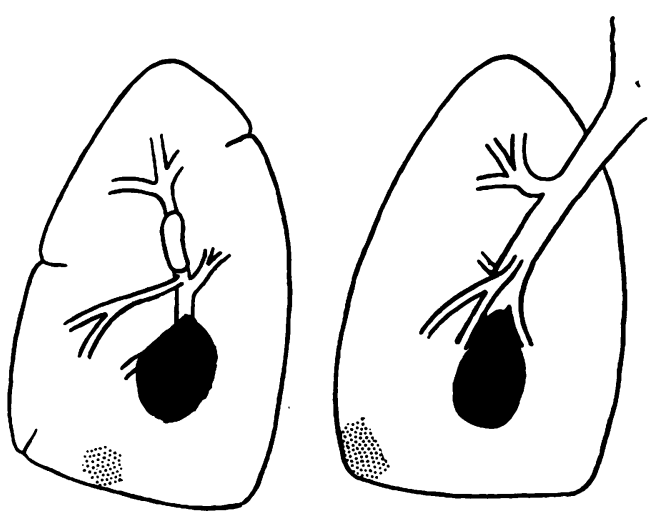

FIG. 20.-Case 9: diagrams of right lung showing positions of carcinoma (black) and infarct (dotted).

The tumour is a large oat-cell carcinoma. The infarct, which shows evidence of septic change, is associated with a long-standing bronchopneumonia and appears moderately old. No neoplastic infiltration or thrombosis of vessels is seen.

CASE 10.-A man of 46 had had winter cough and sputum for 20 years. Three months before, the cough and sputum became worse and there was some

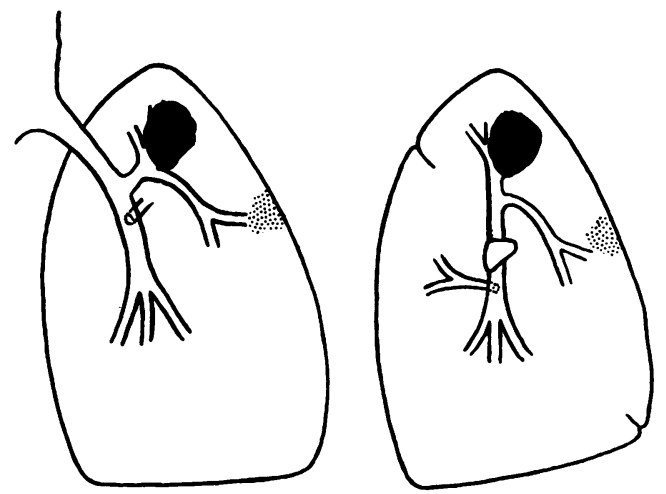

FIG. 21.-Case 10: diagrams of left lung showing positions of carcinoma (black) and infarct (dotted). 
fever. He also had a recent small haemoptysis. Bronchoscopy was normal. Radiographs showed a $3 \mathrm{~cm}$. shadow in the left upper lobe medially and a faint haze in the axilla. (These films, however, were taken three months before the resection. The immediately pre-operative film is unfortunately not available.)

The specimen, a left lung, contained a very necrotic tumour, $4 \times 3.5 \times 3 \mathrm{~cm}$., in relation to the apical and anterior branches of the upper lobe bronchus. Distal to the tumour the lung showed bronchiectasis and emphysema, and there was a peripheral infarct (Fig. 21), $2 \times 2 \times 2 \mathrm{~cm}$, in the superior lingular segment. No thrombosed vessels were found.

The tumour is a squamous cell carcinoma. The infarct is very recent and no causative thrombus is seen.

\section{Summary AND Conclusions}

Ten cases of pulmonary infarction associated with bronchogenic carcinoma are described. These were collected from a series of 100 cases in which pneumonectomy was performed, an incidence of $10 \%$.
In no case was there any evidence of preoperative peripheral venous thrombosis or of pulmonary emboli. There were neoplastic infiltration and thrombosis of main pulmonary arterial branches in two cases and compression of main vessels by tumour tissue in three cases, while the remaining five showed no obvious cause for infarction.

Radiologically, the appearance of the infarcts could be divided into three groups: (1) A welldefined discrete peripheral shadow; (2) a large, wedge-shaped axillary shadow; (3) an infarct not separately identified because of other opacities.

We are indebted to Mr. N. K. Harrison for the photographs and diagrams, Mr. D. F. Kemp for the radiographs, Dr. G. S. Sansom for the photomicrographs, and Mr. J. W. Miller for technical assistance.

\section{REFERENCES}

Massachusetts General Hospital, case 32112. (1946). New Engl. J. Med., 234, 383.

Monges, J., Poinso, R., and Lumbroso, A. (1936). Bull. Soc. méd. Hôp. de Paris, 52, 1355.

Pallasse and Damez (1933). Lyon méd., 151, 227 . 